\title{
Scalp expansion with the Canica Wound Closure System: First case report
}

\author{
Arianna Dal Cin MD, Shane KF Seal MD
}

\begin{abstract}
A Dal Cin, SKF Seal. Scalp expansion with the Canica Wound Closure System: First case report. Can J Plast Surg 2006; 14(4):233-235.
\end{abstract}

The closure of difficult wounds has been an ongoing challenge to the plastic and reconstructive surgeon. New techniques and technology have created innovative methods for this clinical and surgical problem. The Canica Wound Closure System is an external system of tissue expansion that has previously been shown to be successful for delayed abdominal and extremity fasciotomy closures. The hairbearing scalp is unique in that no other tissue in the human body can adequately simulate it. The first known case in North America of a patient in whom the Canica Wound Closure System was used for the successful closure of a large scalp defect following a resection for a Clark level V melanoma is presented.

\section{L'expansion du cuir chevelu à l'aide du Canica Wound Closure System : Premier rapport de cas}

La fermeture des plaies difficiles a toujours été un défi pour le plasticien et le chirurgien reconstructeur. Des nouvelles techniques et technologies ont permis de créer des méthodes novatrices pour contrer ce problème clinique et chirurgical. Le Canica Wound Closure System est un système externe d'expansion tissulaire dont on a déjà démontré l'utilité pour les fermetures abdominales et les aponévrotomies des extrémités. Le cuir chevelu est unique, car aucun autre tissu du corps humain ne peut le simuler correctement. Le premier cas connu en Amérique du Nord d'un patient chez qui on a utilisé le Canica Wound Closure System pour fermer avec succès une large anomalie du cuir chevelu après une résection secondaire à un mélanome de Clark de niveau $\mathrm{V}$ est présenté.

Key Words: External tissue expansion; Scalp

\section{CASE PRESENTATION}

A 30-year-old man was diagnosed with a malignant melanoma of his right anterior scalp in July 2003. It was measured to be $10 \mathrm{~mm}$ in thickness (Clark level V). He underwent wide excision of the tumour in October 2003 with a skin graft for closure. Sentinel lymph node biopsy and lymph node dissection of his neck were negative. He presented in June 2004 to the Plastic Surgery service for consultation regarding potential reconstruction of the skin graft site.

The Canica Wound Closure System (Canica Design Inc, Canada) was offered to the patient along with the other options of subgaleal tissue expanders and rotation flaps. After discussion with the patient and his family, the external expander was chosen. Treatment with this system was commenced in September 2004 and was completed in
February 2005. Application of this system requires an alopecic scalp or a patient willing to shave the scalp bare regularly. The patient was already shaving his scalp to minimize the visibility of the defect and was covering it with a baseball cap.

\section{SURGICAL PROCEDURE AND RESULTS}

A skin graft $8.5 \mathrm{~cm}$ long $\times 7.5 \mathrm{~cm}$ wide covering the excised melanoma defect on the right parietal scalp was assessed for the implementation of the Canica Wound Closure System (Figure 1A). The initial procedure and follow-up visits were conducted in the Day Surgery Unit at the Hamilton General Hospital, Hamilton, Ontario, on an outpatient basis.

Five pairs metallic foot plate anchors, which anchor into the subcutaneous tissue of the scalp, were sutured to the
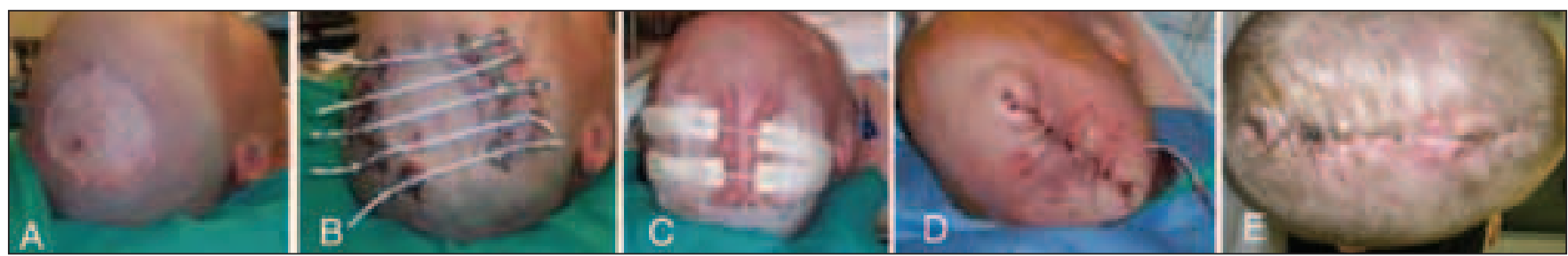

Figure 1) A A skin graft $8.5 \mathrm{~cm}$ long $\times 7.5 \mathrm{~cm}$ wide covering the excised melanoma defect on the right parietal scalp. B Five pairs of metallic foot plate anchors, which anchor into the subcutaneous tissue of the scalp, were sutured to the scalp with 4-0 nylon $5 \mathrm{~mm}$ from the margin of the skin graft on each side of the graft. Five silicone elastomer cords connected each of the five pairs of metallic anchors. The cords were subsequently stretched to 1.5 times their resting length, as assessed by the length markers on the cords. C Weekly visits continued with further reductions in the width of the graft. By day 130, the defect was less than $1 \mathrm{~cm}$. D Wound following excision of the skin graft. The defect was closed with the newly expanded skin using 4-0 nylon. E Healed wound at day 175

McMaster University, Hamilton, Ontario

Correspondence and reprints: Dr Arianna Dal Cin, McMaster University, Victoria Medical Centre, 504-304 Victoria Avenue North, Hamilton,

Ontario L8L 5G4. Telephone 905-526-0811, fax 905-526-0890, e-mail adc.mcedwards@skylinc.net 


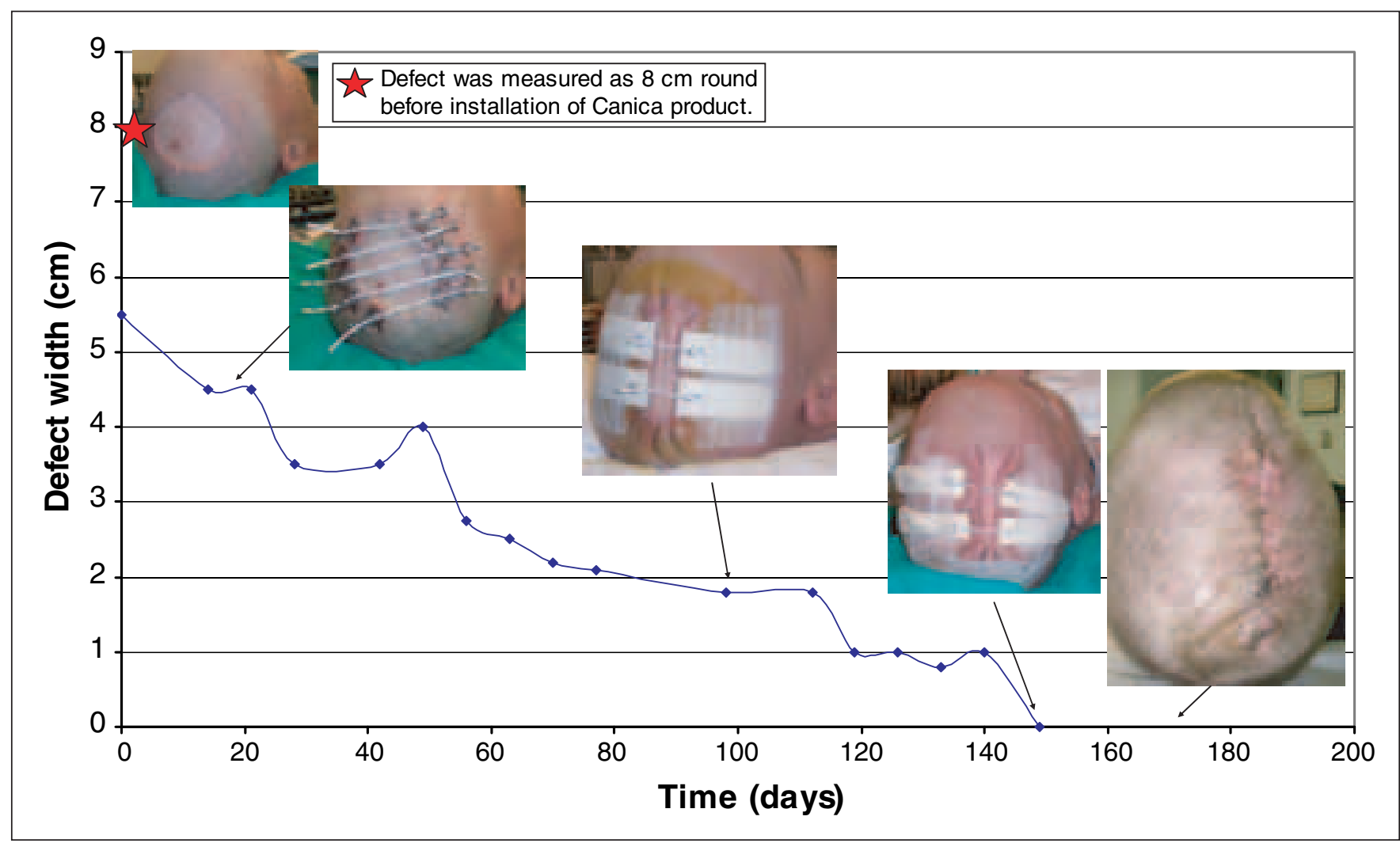

Figure 2) Scalp expansion over the 150 days in this case was generally constant, despite having to revise the metallic anchors with the adhesive anchors

scalp with 4-0 nylon $5 \mathrm{~mm}$ from the margin of the skin graft on each side of the graft. Five silicone elastomer cords connected each of the five pairs of metallic anchors. The cords were subsequently stretched to 1.5 times their resting length, as assessed by the length markers on the cords (Figure 1B). The patient tolerated this initial procedure well. Pain control for the patient at home was managed with oral oxycodone. The patient was seen the following week, when 10 adhesive anchors were placed laterally to the 10 metallic anchors to even out distribution of the surface tension on the scalp.

The patient was monitored on a weekly basis for wound cleansing, further retightening of the elastomer cords and general follow-up. By day 20, several of the metallic anchors were causing superficial tearing of the soft tissues and were resutured onto the scalp. The wound was reduced to $4.5 \mathrm{~cm}$ (60\% reduction) in width within three weeks of the system's implementation. By day 30, the patient remarked on markedly decreased pain that remained true for the remaining duration of the expansion.

Weekly visits continued with further reductions in the width of the graft. By day 40, the width decreased to $3.5 \mathrm{~cm}$. However, only two metallic anchors remained intact without causing underlying soft tissue injury. The other eight were replaced with adhesive anchors from the Canica Wound Closure System. The skin continued to stretch without complications, and by day 100 , the width was $1.8 \mathrm{~cm}$. By day 130 , the defect was less than $1 \mathrm{~cm}$ (Figure 1C). Surgical correction was booked for day 150 .

The excision of the skin graft was performed in the main operating theatre at the Hamilton General Hospital. The defect was closed with the newly expanded skin using 4-0 nylon (Figure 1D). No evidence of scalp blanching was evident to suggest ischemia. A subcutaneous drain was inserted and adhesive tapes reinforced the closure. The patient was seen in follow-up one week later, and the incision at this visit showed excellent approximation. There was no evidence of skin breakdown or infection.

A small area, measuring $5 \mathrm{~mm}$, of dehiscence was noted on day 165 , and was subsequently reinforced with two adhesive anchors. By day 175, a very successful outcome was evident (Figure 1E). A $1 \mathrm{~cm}$ focus of alopecia was noted to be adjacent to the right parietal scalp area in April 2005, with the rest of the scalp showing normal hair regrowth.

\section{DISCUSSION}

Skin elasticity is a function of both elastin and collagen. Elastin provides a limited, initial stretch that is referred to as intrinsic extensibility. Collagen, in addition to providing tensile strength, will show reorientation of its fibres in the plane of pull with continued stretch, and thus affords skin an increased extensibility. The principles of creep and stress relaxation are employed in this case $(1,2)$. Creep occurs when skin exhibits an additional lengthening beyond its intrinsic extensibility and is explained by extrusion of fluid from the dermis and a breakdown of the dermal framework. Creep is divided into mechanical and biological categories. Mechanical creep, occurring within minutes to hours, results in new collagen alignment and decreases skin closure surface tension. Biological creep, occurring in weeks to months, is a viscoelastic property that results in the production of new collagen and 
allows skin to stretch without a change in tension. Stress relaxation in skin also occurs over a long period and is important in tissue expansion. With continued stretching of skin components, the initial force in the initial deformation phase is greater than the force required later to maintain the deformed length. With the patient in this case coming for weekly visits to have the elastomer cords retightened to 1.5 times resting length, the principles of creep and stress relaxation are evident.

The scalp is a unique part of the body, with no other areas of the skin being an adequate graft replacement. Due to its thick galea, hair-bearing surface and thick dermis, grafts for the scalp are often functionally and cosmetically unsatisfactory. The scalp can be expanded up to two times its surface area before showing signs of hair thinning. While subgaleal implants for scalp expansion are a proven, efficacious procedure, they are not without complications. The most common complication, occurring in up to $25 \%$ in some studies, is expander exposure and extrusion (1). Other complications include excessive pain, flap necrosis and cosmetic issues, including skull deformity. In addition, most are two-staged procedures that require a rotation flap for closure (2-5).

Rotation flaps can also be used for certain scalp defects. These are usually smaller defects due to the inelasticity of the galea. Flaps can lead to alteration of hair patterns and increased number of scars, and can compromise dermal blood supply if galeotomies are utilized (3).

External skin expansion has been a successful procedure for delayed extremity fasciotomy sites and abdominal wound closures (6). The present paper supports an additional indication for external expansion. Scalp expansion over the 150 days in this case was generally constant, despite having to revise the metallic anchors with the adhesive anchors (Figure 2).

The final closure of the defect in this case was performed in the main operating theatre at the Hamilton General Hospital and proceeded without any complications. The cosmetic result was excellent, which is equal to or quite possibly better than that seen with subgaleal expanders.
This system provides the plastic and reconstructive surgeon with an easy initial procedure in a day surgery unit, and with subsequent outpatient visits of less than $30 \mathrm{~min}$. Due to its external nature, there is less chance for infection and there are no visible donor scars when it is completed. However, from our perspective, the main disadvantage with this procedure is that it takes significantly longer than what is required for subgaleal expanders. The patient may experience skin breakdown (with metallic anchors) as in this case. This would be a difficult system to apply in a patient who does not have alopecia and does not want to shave his or her scalp. Fortunately, many males are not adverse to shaved scalps due to current male hairstyles.

\section{SUMMARY}

The closure of a scalp defect can often lead to unsatisfactory results when using either internal expanders or rotation flaps. We present the first documented case in North America of external expansion using the Canica Wound Closure System for the closure of a scalp defect. The success of this procedure shows that this system is an excellent option to be considered by the plastic and reconstructive surgeon when correcting a scalp defect, yielding both satisfying cosmetic and functional results.

\section{REFERENCES}

1. Leedy JE, Janis JE, Rohrich RJ. Reconstruction of acquired scalp defects: an Algorithmic approach. Plast Reconstr Surg 2005; 116:54e-72e

2. Argenta LC. Tissue expansion. In: Aston SJ, Beasley RW, Thorne CHM, eds. Rabb and Smith's Plastic Surgery, 5th edn. Phildelphia: Lippincott-Raven Publishers, 1997:91-7.

3. Earnest LM, Byrne PJ. Scalp reconstruction. Facial Plast Surg Clin North Am 2005;13:345-53.

4. Argenta LC, Austad ED. Principles and techniques of tissue expansion. In: McCarthy JG May JW Jr, Littler JW, eds. Plastic Surgery. Phildelphia: WB Saunders Company, 1990:475-507.

5. Seline PC, Siegle RJ. Scalp reconstruction. Dermatol Clin 2005;23:13-21.

6. Caruso DM, King TJ, Tsujimura RB, Weiland DE, Schiller WR. Primary closure of fasciotomy incisions with a skin-stretching device in patients with burn and trauma. J Burn Care Rehabil 1997;18:125-32. 